\title{
Water stress and water use efficiency of ten white clover cultivars
}

\author{
M. BARBOUR ${ }^{1}$, J.R. CARADUS ${ }^{2}$, D.R. WOODFIELD ${ }^{2}$ and W.B. SILVESTER ${ }^{1}$ \\ ${ }^{1}$ Dept. of Biological Sciences, University of Waikato, Private Bag 3105, Hamilton \\ ${ }^{2}$ AgResearch Grasslands, Private Bag 11008, Palmerston North
}

\begin{abstract}
Ten cultivars of white clover were grown in a glasshouse at three levels of soil moisture. Leaf productivity was greatly reduced by moisture stress. The productivity of cultivars was found to be significantly different under well-watered conditions. Larger-leaved cultivars tended to be more productive than those with smaller leaves, but this difference was lost at high moisture stress creating a significant cultivar by moisture treatment interaction. Water use efficiency (WUE) increased with increasing moisture stress, but within any one moisture level there were no significant differences between the cultivars. An integrated measure of WUE is captured by the level of discrimination against ${ }^{13} \mathrm{C}$ in plants tissue $(\Delta)$. Over the range of moisture levels used, a strong negative correlation was found between $\Delta$ and WUE. A strong positive correlation was found between productivity and $\Delta$ over the range of moisture treatments, however, within any one moisture level no significant relationship was established.
\end{abstract}

Keywords: carbon isotope discrimination, cultivars, moisture stress, Trifolium repens, water use efficiency

\section{Introduction}

Moisture stress is one of the most important constraints on the growth and persistence of white clover (Trifolium repens L.) in many areas of New Zealand, particularly dry hill country and along the east coast (Williams et al. 1990). Significant reductions in leaf dry weight have been recorded for white clover in response to increased moisture stress (Turner 1991). White clover has been recognised as a species with poor control of water loss, leaf diffusive resistance does increase with developing water stress but not sufficiently to prevent transpiration continuing (Hart 1987).

Several recent studies have looked at drought tolerance in white clover. Improved productivity and persistence under low soil moisture conditions have been found in populations collected from drought prone areas (Woodfield \& Caradus 1987). These populations were also more taprooted than expected from their shoot morphology (Caradus \& Woodfield 1986), although selecting for root morphology per se was found to be less effective in improving drought tolerance than screening in drought-prone areas (van den Bosch et al. 1993). A high level of plant recovery from buried stolons has also been implicated in improved drought tolerance (Chapman \& Williams 1990), as has the production of large nodal roots (Macfarlane et al. 1990).

During water stress plants generally close their stomata with resultant reduced water loss, decreased photosynthesis and an overall apparent increase in water use efficiency (moles of carbon fixed per mole of water transpired). As stomata close $\mathrm{CO}_{2}$ concentration within the leaf $\left(\mathrm{c}_{\mathrm{i}}\right.$ ) lowers and the ratio of ${ }^{13} \mathrm{C} /{ }^{12} \mathrm{C}$ assimilated in photosynthesis is altered. In low $c_{i}$ (i.e. water stressed plants) ribulose bisphosphate carboxylase (Rubisco) fixes proportionally more ${ }^{13} \mathrm{CO}_{2}$ so the level of discrimination against ${ }^{13} \mathrm{C}(\Delta)$ is lowered. Water use efficiency is thus strongly negatively correlated with water use efficiency. This correlation has been found in wheat (Farquhar \& Richards, 1984), peanut (Hubick et al. 1986) and sunflower (Lauteri et al. 1993). $\Delta$ is seen as a useful tool in plant selection for drought tolerance and as a measure of relative water stress because it is easier and quicker to measure than water use efficiency.

This research investigated relationships between $\Delta$, WUE and productivity, with the objective of assessing the applicability of carbon isotope techniques in breeding for increased drought tolerance in white clover. Several cultivars of white clover have been produced by traditional breeding techniques that may have significant drought tolerance and are assessed in this study.

\section{Materials and methods}

Ten cultivars of white clover (Table 1) were grown under three soil moisture levels in 5L buckets without drainage with five replicates. The Ballantrae soil was chosen for low nitrogen content and free-draining properties. Fertiliser was added to the soil to correct all deficiencies except nitrogen, and the soil was packed into buckets to a bulk density of $0.889 \mathrm{gcm}^{-3}$. Plants were sown ten to a pot and allowed to establish for 27 days, during which the soil moisture level was maintained at just under field capacity. Pots were then clipped to 5\% leaf area and arranged in the science glasshouse at the University of Waikato in a randomised split plot design. 
Table 1: Description of cultivars.

\begin{tabular}{clllll}
\hline Label & Cultivar & Leaf size & Stolon density & Growth habit & Origin \\
\hline a & Prop & small & high & prostrate & NZ, dry hill country \\
b & Grasslands Tahora & small & high & prostrate & NZ, wet hill country \\
c & Grasslands Prestige & medium/small & high & prostrate & NZ, Northland \\
d & Sonja & medium/large & low & long stolons & Sweden \\
e & Grasslands Huia & medium & intermediate & intermediate & $\mathrm{NZ}$ \\
f & Grasslands Sustain & medium/large & high & mod. erect & $\mathrm{NZ}$ \\
$\mathrm{g}$ & Grasslands Kopu & large & mod. low & erect, open & $\mathrm{NZ}$ \\
h & Haifa & large & mod. low & mod. erect, open & Israel \\
& Brown Loam Syn & very large & mod. low & Ladino, erect & USA \\
j & Dusi & very large & mod. low & Ladino, erect & South Africa \\
\hline
\end{tabular}

When the plants had been set up in the glasshouse and allowed to equilibrate for 10 days, soil moisture stress was imposed, all pots reaching the required moisture level within 8 days. The moisture levels were 53, 45 and $19 \%$ soil moisture by weight, field capacity of the soil being $60 \%$ soil moisture, and were maintained by weighing every second day. Pots were moved in replicate groups every time they were weighed to ensure environmental variation due to position in the glasshouse was eliminated.

Two harvests 'were made, the first 30 days after establishment of moisture levels, of leaf and petiole material only. All pots were then rewatered to $53 \%$ soil moisture and maintained for 8 days. Plants were again clipped to 5\% leaf area and moisture levels imposed once again. During the second drought period the soil moisture levels were 53, 39 and 19\% soil moisture. The intermediate moisture level was lowered in an attempt to separate WUE and A in control and moderately stressed plants. The second drought period lasted 24 days, after which the plants were destructively harvested. Water use efficiency was calculated as the ratio of $g$ leaf dry matter and $\mathrm{kg}$ water used.

Leaf samples were taken for carbon isotope analysis at both harvests. The dried and ground samples were analysed on a Dumas method elemental analyser (NA1500, Carlo Erba Strumentazione, Italy) interfaced to a stable isotope mass spectrometer (Tracermass, Europa Scientific Ltd., UK) at the Waikato Stable Isotope Unit, University of Waikato.

\section{Results}

\section{Productivity}

Leaf dry matter was significantly and progressively reduced by increasing moisture stress (Figure I). Under well-watered conditions (53\% soil moisture) significant differences in productivity between cultivars were found, the larger leaved cultivars tending to be more productive than those with smaller leaves. Under high moisture stress (19\% soil moisture) these differences were not apparent, all cultivars having approximately equal productivity (Figure 1). As the cultivars responded differently to moisture stress a significant cultivar by moisture treatment interaction was found, the largerleaved cultivars generally being more sensitive to moisture stress.

Figure 1: Mean $(n=5)$ leaf dry weight per pot of cultivars ranked $a-j$ according to leaf size, at the second harvest. Mean standard error $=0.89 \mathrm{~g}$. Cultivars are significantly different $(\mathrm{p}<0.05)$ at 53 and $39 \%$ soil moisture. Cultivar by moisture treatment interaction; $\mathrm{p}=0.0015$.

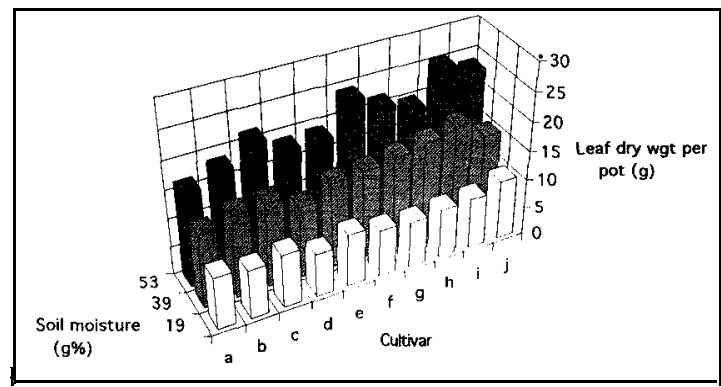

\section{Water use efficiency}

WUE increased under high moisture stress (Figure 2). WUE was not significantly different for cultivars under intermediate soil moisture levels and control conditions. Within any one moisture level no significant differences in WUE were found between cultivars.

\section{WUE vs A}

Carbon isotope discrimination was significantly reduced by moisture stress. No differences between cultivars were found within moisture treatments. A strong negative correlation $(r=-0.876)$ was found between WUE and A. However, within any one moisture level no relationship was established (Figure 2). A similar 
Figure 2: The relationship between discrimination and WUE at the second harvest. Values are means, Mean standard errors of WUE and A are 0.21 and 0.28 respectively. $\square=53 ; 0=39 ; 0=19 \%$ soil moisture. $\mathrm{y}=30.27$ $1.279 x . r=-0.876$.

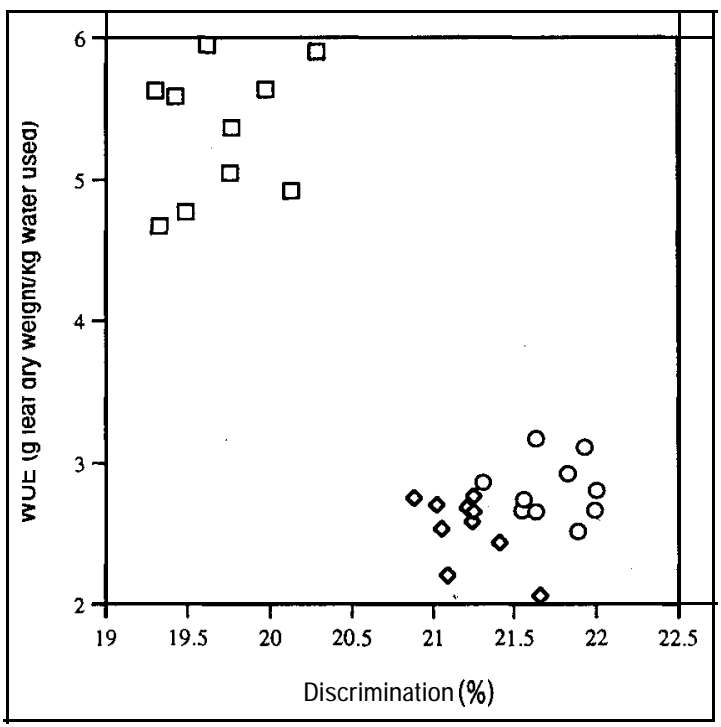

result was found for both harvests (harvest 1 data not shown).

\section{Productivity vs $A$}

A strong positive correlation $(\mathrm{r}=0.879)$ was found between productivity and A over the range of moisture levels. However, within the individual moisture levels no relationship could be established (Figure 3) because cultivars did not have significantly different $\mathrm{A}$. That is A failed to discriminate between the significantly different productivity in well-watered plants. Similar results were found for both harvests (harvest 1 data not shown).

\section{Discussion}

WUE of cultivars within moisture level showed no significant differences, indicating little genetic variability in photosynthetic capacity and control of water loss, the parameters that define WUE, between the cultivars under these experimental conditions. Despite larger-leaved cultivars tending to be more productive than smallerleaved varieties they also used more water and so showed no increase in water use efficiency. A, an integrated measure of WUE, supports this conclusion. A decreased as moisture stress increased, but no significant differences between cultivars were found within a moisture level.
Figure 3: The relationship between discrimination and leaf dry weight at the second harvest. Values are means, $\mathrm{n}=\mathbf{5}$, Mean standard errors of leaf dry weight and $\mathrm{A}$ are 0.89 and 0.28 respectively. $\square=53 ; 0=39 ; 0=19 \%$ soil moisture. $y=5.233 x-94.280 . r=0.879$.

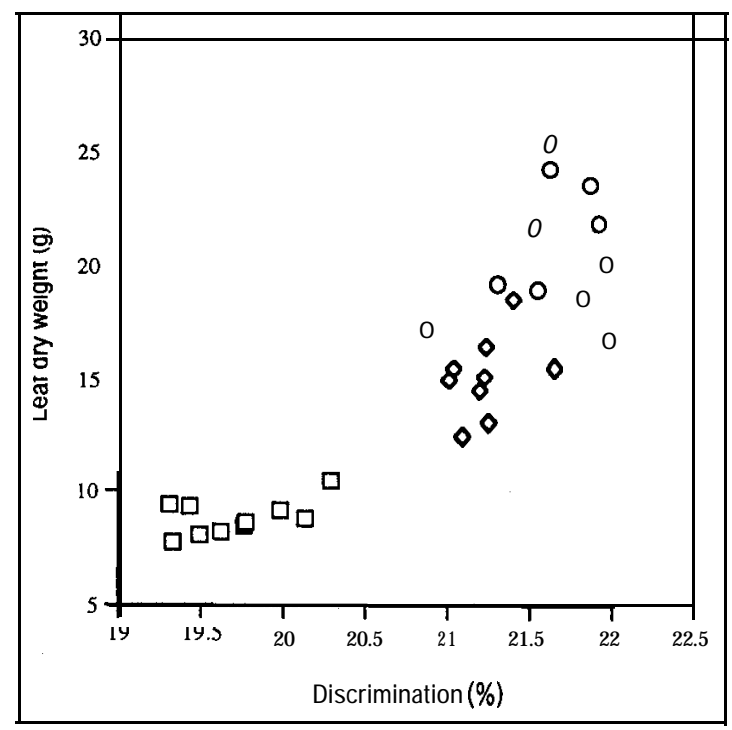

As in species such as wheat (Farquhar \& Richards 1984) and peanut (Hubick et al. 1986), a negative correlation was found between A and WLJE. While this relationship was robust over the range of soil moisture levels, no relationship was found within a moisture level, due to the lack of significant differences between cultivars for either WUE or A. The correlation implies that the WUE of a clover plant in the field may be predicted from A. A strong positive correlation was found between A and productivity over the range of moisture levels. This relationship also has potential predictive power.

Predicting productivity and WUE from A would greatly reduce the time and effort currently employed to measure these factors in large-scale screening trials. However, a number of factors must be considered before isotope technology can be used. The first consideration is that environmental conditions, both climatic and soil, vary considerably from one trial to another, and these variations will greatly affect A. For WUE and productivity to be accurately predicted from A, calibration measurements must be taken under the environmental conditions of the trial. The second factor that must be considered is the age of the leaf to be analysed. It is the isotopic ratio of carbon fixed during the period of interest that must be analysed, not the ratio of the leaves that are fixing carbon. Older leaves may have been formed from carbon fixed during a rather different 
set of environmental conditions, e.g. pre-drought, rather than the environ-mental conditions currently affecting the plant.

The level of self-shading within a canopy must also be considered. As plant growth progresses through a season the level and quality of light reaching the lower leaves is reduced by self-shading. The reduction in light affects the photosynthetic rate, and so affects $\Delta$. Therefore, care must be taken to harvest only leaves from a similar light environment for carbon isotope analysis. Other considerations outlined by Farquhar et al. (1989), such as spatial variation of $\mathrm{CO}_{2}$ within a canopy, do not apply to white clover as the whole plant is within the earth boundary layer, so all leaves would be in a similar $\mathrm{CO}_{2}$ environment.

While little genetic variability was found in WUE and $\Delta$ between cultivars in this experiment, we suggest that there may be as much variation in WUE and $\Delta$ between genotypes of the same cultivar as between cultivars. This intra-cultivar variation may prove to be more important in terms of breeding for drought tolerance than inter-cultivar variation.

\section{Acknowledgements}

This research was carried out under a grant from the Foundation for Research, Science and Technology, contract C10310. Financial assistance from the C. Alma Baker Trust is also gratefully acknowledged. R. Martindale and M. Auger are thanked for technical assistance, and A. Rajendram for stable isotope analysis.

\section{References}

Barker, D.J.; Caradus, J.R.; McManus, M.T. 1993. Physiological responses of white clover genotypes to water deficit. Proceedings International Grasslands Congress 17: 67-68.

Caradus, J.R.; Woodfield, D.R. 1986. Evaluation of root type in white clover genotypes and populations. Agronomy Society of New Zealand Special Publication No. 5: 322-325.

Chapman, D.F.; Williams, W.M. 1990. Evaluation of clovers in dry hill country 9. White clover at "Ballantrae", and in central Wairarapa, New Zealand. New Zealand Journal of Agricultural Research 33: 577-584.
Farquhar, G.D.; Ehleringer, J.R.; Hubick, K.T. 1989. Carbon isotope discrimination and photosynthesis. Annual Review of Plant Physiology and Plant Molecular Biology 40: 503-552.

Farquhar, G.D.; Richards, R.A. 1984. Isotopic composition of plant carbon correlates with water use efficiency of wheat genotypes. Australian Journal of Plant Physiology 11: 537-552

Hart, A.L. 1987. Physiology. pp. 125-151. In: Baker M.J.; Williams W.M. (eds). White Clover, C.A.B. International, Wallingford, UK.

Hubick, K.T.; Farquhar, G.D.; Shorter, R. 1986. Correlation between water use efficiency and carbon isotope discrimination in diverse peanut (Arachis) germplasm. Australian Journal of Plant Physiology 13: 803-16.

Lauteri, M.; Brugnoli, E.; Spaccino, L. 1993. Carbon isotope discrimination in leaf soluble sugars and in whole-plant dry matter in Helianthus annuus L. grown under different moisture conditions. In: Ehleringer, J.R.; Hall, A.E.; Farquhar, G.D. (eds). Stable isotopes and plant carbon-water relations. Academic Press, Inc.

Macfarlane, M.J.; Sheath, G.W.; McGowan, A.W. 1990. Evaluation of clovers in dry hill country 5. White clover at Whatawhata, New Zealand. New Zealand Journal of Agricultural Research 33: 549-556.

Turner, L.B. 1991. The effect of water stress on the vegetative growth of white clover (Trifolium repens L.): comparison of long-term water deficit and a short-term developing water stress. Journal of Experimental Biology 42: 311-16.

van den Bosch, J.; Black, I.K.; Cousins, G.R.; Woodfield, D.R. 1993. Enhanced drought tolerance in white clover. Proceedings of the New Zealand Grassland Association 55: 97-101.

Williams, W.M.; Sheath, G.W.; Chapman, D.F. 1990. Evaluation of clovers in dry hill country 1 . General objectives and description of sites and plant material. New Zealand Journal of Agricultural Research 33: 521-26.

Woodfield, D.R.; Caradus, J.R. 1987. Adaptation of white clover to moisture stress. Proceedings of the New Zealand Grasslands Association 48: 143-145. 